3) Devir, S. E.: J. Colloid and Interface Sci., 21, 80 (1967).

4) Fuchs, N. A.: "The Mechanics of Aerosols", p. 305, Pergamon Press, Oxford (1964).

5) Gillespie, T: Proc. Roy. Soc., 216, 569 (1953).

6) Kanagawa, A. and T. Takahashi: Kagaku Kogaku Ronbunshu, 4, 446 (1978).
7) Kousaka, Y., K. Okuyama, M. Adachi and K. Ebie: $J$. Chem. Eng. Japan, 14, 54 (1981).

8) Kraemer, H. F. and H. F. Johnstone: Ind. Eng. Chem., 47, 2426 (1955).

9) Whytlaw-Gray, R. W.: Proc. Roy. Soc., 124, 523 (1929).

10) Zebel, G.: Kolloidzeitschrift, 157, 37 (1958).

\title{
NUTRIENT LIMITATIONS ON BIODEGRADATION OF $n$-HEXADECANE BY BACILLUS SP., A CANDIDATE ORGANISM IN SEEDING
}

\author{
YASUSH KAWAKAMI AND HAJIME NISHIMURA \\ Department of Chemical Engineering, Faculty of Engineering, \\ University of Tokyo, Tokyo 113
}

\begin{abstract}
The limitation of nutrient concentrations on degradation of $n$-hexadecane by marine Bacillus sp. was investigated by use of a semi-batch incubation system. This bacterium is a candidate organism for seeding, i.e. artificial enhancement of biodegradation of spilled oils. The degradation rate did not change greatly from $244 \mu$ mol-total inorganic $\mathrm{N}$ (TIN) $/ l$ and $6.5 \mu \mathrm{mol}-\mathrm{PO}_{4}-\mathrm{P} / l$ down to $4 \mu \mathrm{mol}-\mathrm{TIN} / l$ and $0.4 \mu \mathrm{mol}-\mathrm{PO}_{4}-\mathrm{P} / l$, respectively. But at $2 \mu \mathrm{mol}-\mathrm{TIN} / l$ and $0.3 \mu \mathrm{mol}-\mathrm{PO}_{4}-\mathrm{P} / l$, it decreased rapidly to as low as one-tenth of that with higher $\mathbf{N}$ and $\mathbf{P}$ concentrations. Both degradation rate and cell growth were approximated by the same Michaelis-Menten form equations. The concentration where the rate was reduced to half was $3 \mu \mathrm{mol}-T I N / l$. The nitrogen uptake rate was proportional to nitrogen concentration.

Retardation of biodegradation at the sea surface due to poor nutrient transport from underlying water was evaluated using a simple model and was shown to be small. Accordingly, the application of fertilizer is generally unnecessary in eutrophic coastal seas when this bacterium is used as seed organism.
\end{abstract}

\section{Introduction}

Oil pollution in coastal seas and in the ocean have aroused interest in the biodegradation of petroleum hydrocarbons by marine microorganisms ${ }^{1,17,22}$. Artificial enhancement of the biodegradation of petroleum has been proposed to remove spilled oils on the $\mathrm{sea}^{6,7,23)}$. Data on such biodegradation has been obtained from laboratory experiments and is available for the assessment of the effectiveness of seeding $^{1,9}$. Considerable differences, however, might exist between the conditions of laboratory experiments and those of actual processes in situ. Among these conditions, the difference in nutrient concentrations such as those of nitrogen and phosphorus between natural seawater and enriched media is remarkable ${ }^{11}$; laboratory media usually have one thousand to ten thousand-fold higher nutrient levels than natural seawater. Those nutrients have to be supplied from the seawater because petroleum contains only small amounts of these elements. Supplementaion of

Received November 20, 1980. Correspondence concerning this article should be addressed to Y. Kawakami. fertilizers is emphasized to overcome the nutrient limitation in seeding on the basis of results of several investigations ${ }^{2,3)}$. However, those results were obtained either by batch incubation or by flow-through outdoor systems and seem less reliable for several reasons. In seeding, an important point is to know the threshold concentrations of nutrients below which the growth of seed microbes becomes limiting. If these concentrations are lower than the environmental levels, application of fertilizer will be unnecessary and even harmful. Continuous culture is ideal for this purpose, yet it is difficult to make a continuous system with small input of oil and to measure the oil consumption in this system. Therefore, we adopted a semi-batch cultivation with successive addition of nutrients to learn the threshold concentrations of nutrients for the oil-degrading bacterium Bacillus sp., a candidate organism in seeding.

\section{Materials and Methods}

\subsection{Organism}

The bacterium used in this study, dentified as Bacillus sp., was isolated from seawater from the 


\begin{tabular}{lcccl} 
Table 1 & $\begin{array}{c}\text { Initial nutrient concentration in media } \\
\text { Set } \\
\text { number }\end{array}$ & Nitrogen & $\begin{array}{c}\text { Phos- } / l] \\
\text { phorus }\end{array}$ & $\begin{array}{c}\text { Seawater } \\
\text { source }\end{array}$ \\
\hline 1st experiment & I & 244 & 6.5 & Keihin \\
2nd experiment & II & 57.7 & 1.0 & Canal \\
& III & 50 & 5 & \\
& IV & 15 & 1.5 & Kuroshio \\
& V & 5 & 0.5 & \\
& VI & 2 & 0.3 & \\
\hline
\end{tabular}

Keihin Canal in Tokyo Bay. High viability and storability in the form of dried cells are the basic requirements for a seed organism, and some commercial lyophilized cells were proved to have poor viability ${ }^{4}$. Bacillus forms an endospore, which retains its viability for a long time and germinates rapidly. This Bacillus also showed nearly $10 \%$ viability, much higher than the commercial cells ${ }^{14}$.

\section{2 Seawater and chemicals}

Seawater collected from the Keihin Canal and from a station in the Kuroshio (Japan Current) off

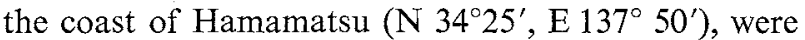
used as the media for the first and the second experiments, respectively. The water from the Keihin Canal was aged over 6 months, but that from the Kuroshio was aged only one month. The seawaters were filtered through glass fiber filters (Whatman GF/C) before use. $n$-Hexadecane was auto claved and reagent-grade chemicals were used throughout.

\subsection{Media}

The nutrient concentrations in the media are shown in Table 1. As much as $10 \mu \mathrm{g} / \mathrm{l}$ yeast extract was added to the seawater from Kuroshio, which was enough to supply trace nutrients but not enough to support bacterial growth as a carbon source. All media were autoclaved before use.

\section{4 Incubation}

Incubation Several $500-\mathrm{m} l$ Erlenmeyer flasks, each containing $100 \mathrm{~m} l$ of a medium and $1 \mu l n$-hexadecane, were prepared. These constituted a sample set. The flasks of the first experiment ( 2 sets) and those of the second experiment (4 sets) were incubated at a time, respectively. The flasks from set I and II in the first experiment were inoculated with 20 cells/ $\mathrm{m} l$ which had been harvested from a flask incubated for 3 days with medium I. Cells numbering as many as $2 \times 10^{5}$ cells $/ \mathrm{m} l$ that had been grown in medium III for 3 days were pipetted into the flasks for the second experiment. The flasks were placed on a rotary shaker with a speed of $210 \mathrm{rpm}$, in a room at $25 \pm 2^{\circ} \mathrm{C}$. This temperature is typical of surface seawaters around Japan in summer. To maintain constant nutrient concentrations in the flasks during incubation, one-sixth the amount of the initial nutrients in each flask was repeatedly added in $0.1 \mathrm{~m} l$ portions to all the remain- ing flasks of the second experiment, while observing the progress of cell growth. No supplementary nutrients were added to the flasks in the first experiment during incubation. Several additional runs with higher $n$-hexadecane dosages and with a medium containing $0.5 \mathrm{~g} \mathrm{KNO}_{3} / l$ and $1.5 \mathrm{~g} \mathrm{Na}_{2} \mathrm{HPO}_{4} / l$ were carried out to examine the dependence of degradation rates on hydrocarbon dosage.

\subsection{Determination of hydrocarbon and nitrate con- centration}

Residual hydrocarbon in the flasks was extracted with three changes of cyclohexane. After drying over anhydrous sodium sulfate, the extract was concentrated to near-dryness with a rotary evaporator. It was transferred to a test tube and diluted to $5-10 \mathrm{ml}$. Two microliters was injected into a gasliquid chromatograph equipped with dual flameionization detectors and dual $3 \mathrm{~m} \times 2 \mathrm{~mm}$ I.D. stainless steel columns packed with $5 \%$ silicone OV-1 on Chromosorb W, 60/80 mesh. The columns were temperature-programmed from $150^{\circ} \mathrm{C}$ to $250^{\circ} \mathrm{C}$ at a rate of $10^{\circ} \mathrm{C} / \mathrm{min}$. The sample port was heated to $350^{\circ} \mathrm{C}$ and $\mathrm{N}_{2}$ carrier gas was used at a flow rate of $40 \mathrm{ml} / \mathrm{min}$. The nitrate in the residual aqueous phase was determined using a cadmium-copper reducing column according to the method of Strickland and Parsons ${ }^{21)}$. Ammonia, nitrite and phosphate concentrations in the seawater used for media were determined by the method cited above. Cell numbers were counted using a counting chamber.

\section{Results}

\section{1 The effect of nutrient concentrations on $n$-hexa- decane degradation}

Bacillus degraded $1 \mu l / 100 \mathrm{~m} l$ of $n$-hexadecane in 1.5 days in the first experiment, as shown in Fig. 1. Cell growth reached $6.1 \times 10^{7}$ cells $/ \mathrm{m} l$ for set $I$ after 48 hours and the doubling time calculated on the assumption that logarithmic cell growth began without a lag phase was about 2.2 hours in this run. The difference in nutrient concentrations between medium $\mathrm{I}$, with $244 \mu \mathrm{mol}$ inorganic $\mathrm{N} / l$ and $6.5 \mu \mathrm{mol} \mathrm{PO}_{4}^{-}$ $\mathrm{P} / l$, and medium II, with $58 \mu \mathrm{mol}$ inorganic $\mathrm{N} / l$ and $1 \mu \mathrm{mol} \mathrm{PO}_{4}-\mathrm{P} / l$, did not affect the degradation rate.

The results of the second experiment with lower nutrient levels are shown in Fig. 2. Wedges shown at positions along the abscissa denote the times at which nutrients were added during the incubation. Among sets III, IV and V, the hydrocarbon content decreased in a similar fashion, whereas the decrease in set VI, with $2 \mu \mathrm{mol}$ nitrate $\mathrm{N} / l$ and $0.3 \mu \mathrm{mol} \mathrm{PO}_{4}-\mathrm{P} / l$ was about one-tenth that of the other sets. For the former three sets, the degradation rates during the period indicated by the bracket in Fig. 2, when a rapid disappearance of hydrocarbon took place, were similar to 


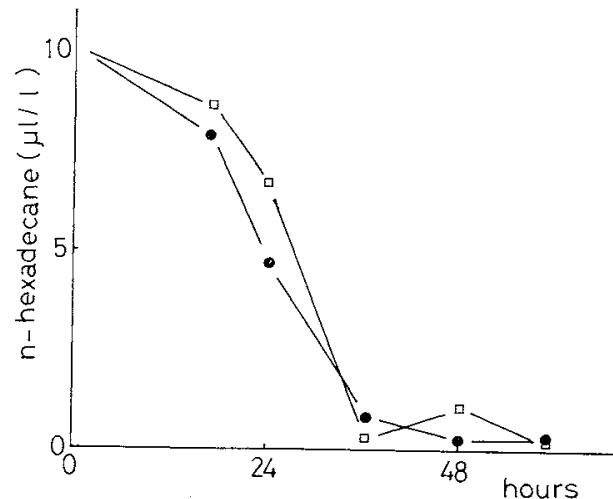

$\square$, set I $\left(244 \mu \mathrm{mol}-\mathrm{TIN} /{ }^{\circ}, 6.5 \mu \mathrm{mol}_{-} \mathrm{PO}_{4}-\mathrm{P} / \mathrm{l}\right)$

•, set II $\left(57.7 \mu \mathrm{mol}-\mathrm{TIN} / l, 1 \mu \mathrm{mol}-\mathrm{PO}_{4}-\mathrm{P}\right)$

Fig. 1 -Hexadecane degradation by Bacillus sp. (first experiment)

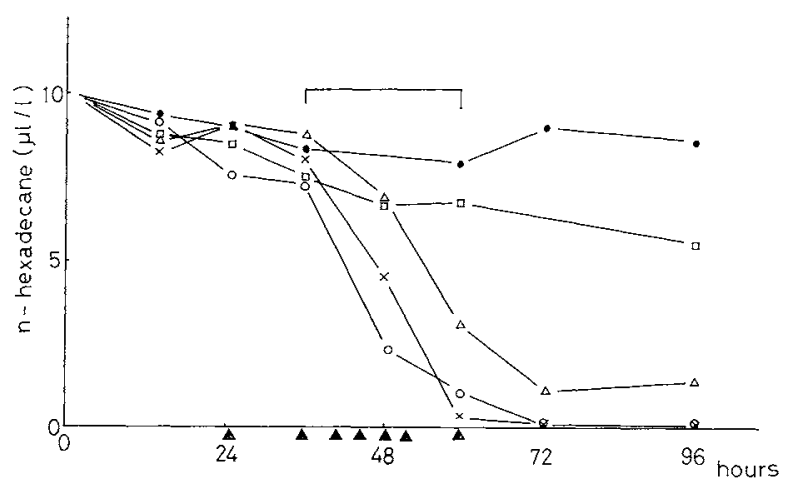

火, set III $(50 \mu \mathrm{mol}-\mathrm{N} / l, 5 \mu \mathrm{mol}-\mathrm{P} / l)$

$O$, set IV $(15 \mu \mathrm{mol}-\mathrm{N} / l, 1.5 \mu \mathrm{mol}-\mathrm{P} / l)$

$\Delta$, set V $(5 \mu \mathrm{mol}-\mathrm{N} / l, 0.5 \mu \mathrm{mol}-\mathrm{P} / l)$

$\square$, set VI $(2 \mu \mathrm{mol}-\mathrm{N} / l, 0.3 \mu \mathrm{mol}-\mathrm{P} / l)$

- control

Wedges under abscissa indicate nutrient additions. Bracketed period was used for calculation of degradation rates and nutrient uptake rates.

Fig. 2 n-Hexadecane degradation by Bacillus sp. (second experiment)

those of previous experiments without nutrient supplement. However, the degradation in these three sets occurred about a day later than in the previous run, even though the amount of inoculum was ten thousand times larger. The nutrient concentrations below which the degradation rate decreased sharply were lower than those of the canal water from which the Bacillus was isolated. The total inorganic nitrogen was $12 \mu \mathrm{mol} / l$ and the $\mathrm{PO}_{4}-\mathrm{P}$ was $0.8 \mu \mathrm{mol} / l$. The media for screening and preculturing had much higher nutrient concentrations.

Figure 3 shows the changes of nitrate concentration during incubation. The changes indicate a balance of nitrate between the original stock, supplements and consumption by microbes. The slope between supplements was drawn on the assumption of constant uptake rates of nitrate. Although any noticeable change in nitrate concentration was undesirable in the

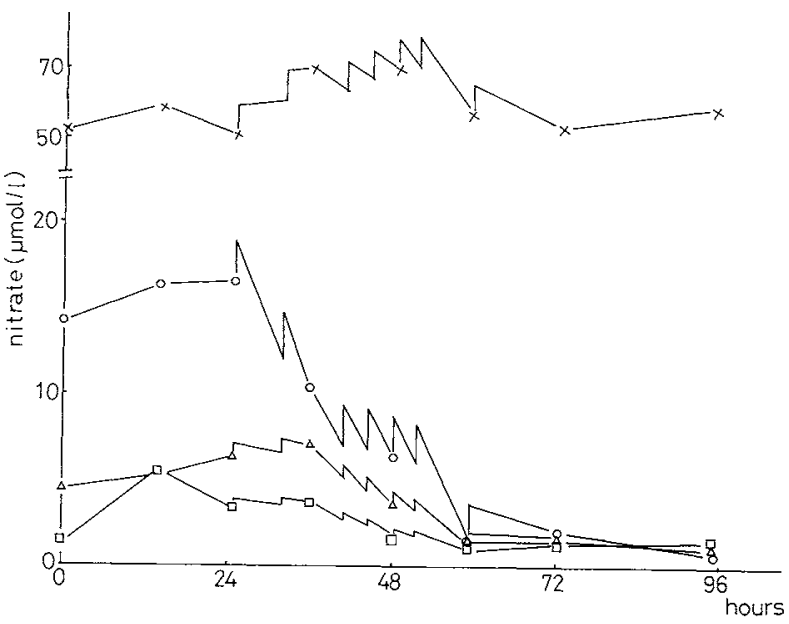

Symbols are the same as those in Fig. 2.

Fig. 3 Changes in nitrate concentrations in media of second experiment

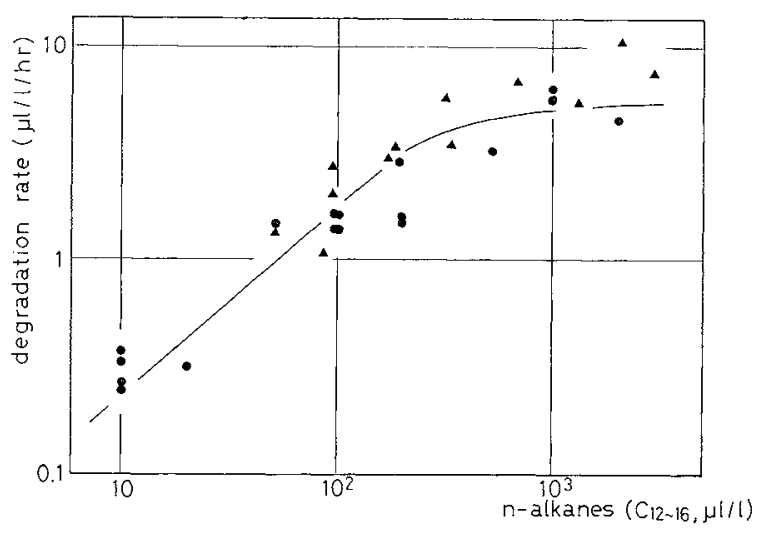

-, Bacillus sp. (substrate was $n$-hexadecane)

A, Caulobacter sp. (substrate was mixture of $n$-alkanes, $\mathrm{C}_{13}-\mathrm{C}_{16}$, after Murakami et al. ${ }^{17)}$; density of mixture is assumed as $0.765 \mathrm{~g} / \mathrm{ml}$.)

Fig. 4 -Alkane degradation rates with different concentrations of hydrocarbons in enriched media

course of cultivation, the concentrations of sets IV and $\mathrm{V}$ could not be maintained even by successive additions, so they were finally dropped. During the period shown by the bracket in Fig. 3, however, each set was at different nitrate levels. It is noteworthy that sets III and V showed similar rates of degradation regardless of large differences in nitrate concentration and that the slight difference in nitrate level between sets $\mathrm{V}$ and VI brought about considerable difference in degradation rates.

The $n$-hexadecane remained in a slick and was undispersed until most of it was removed from the medium surface in the flasks with $1 \mu l / 100 \mathrm{~m} l$ dosage. Cells grown on the surface formed a thin scum and then dispersed into the medium. Vigorous emulsification occurred during incubation in the flasks with higher dosages of hydrocarbon and nutrients. Degradation rates increased with increasing dosage of hydrocarbon 


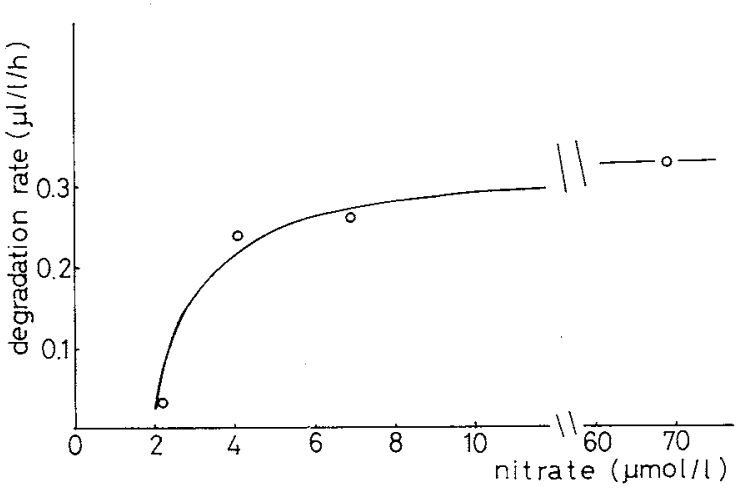

Fig. 5 Changes in degradation rate of $n$-hexadecane with nitrate concentration

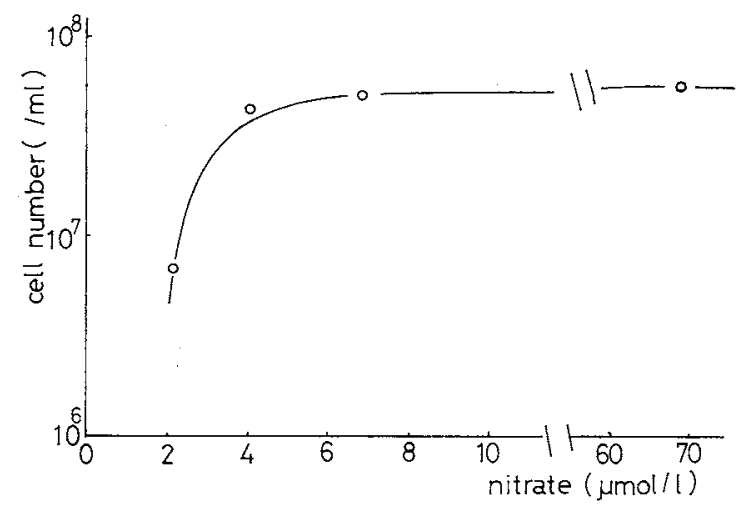

Fig. 6 Changes in cell number with nitrate concentration

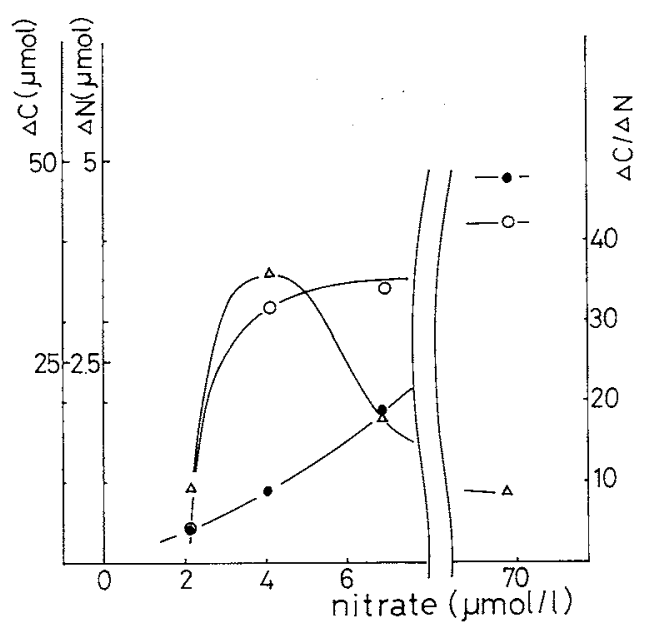

Consumed carbon $(\Delta C)$; Consumed nitrogen $(\Delta \mathrm{N}) ; \triangle$, Their ratio $(\Delta C / \Delta N)$

Fig. 7 Changes in Consumed Carbon and Nitrogen with Nitrate Concentration

up to $200-500 \mu l / l$, the rates gradually levelling off in this dosage range (Fig. 4).

\section{2 Cell growth}

Figure 5 shows the degradation rate during the bracketed period and Fig. $\mathbf{6}$ shows the cell number in the samples taken at the end of the period for each set. The degradation rates were calculated from the decrease of hexadecane during the period. The values of nitrate concentration on the abscissa in these figures are averaged ones throughout the period. Both degradation rate and number of cells, shown in Fig. 5 and Fig. 6, respectively, were approximated by the same Michaelis-Menten form Eqs. (1) and (2), when the initial $n$-hexadecane dosage was $10 \mu l / l$.

$$
\begin{aligned}
& r=r_{\text {max }} \frac{C_{N}-C_{N_{0}}}{K_{N}+\left(C_{N}-C_{N_{0}}\right)} \\
& r_{\max }=0.33 \mu l / l \cdot h \\
& C_{N_{0}}=1.8 \mu \mathrm{mol} / l \\
& K_{N}=1.2 \mu \mathrm{mol} / l \\
& n=n_{\max } \overline{C_{N}-C_{N_{0}}-\left(\overline{C_{N}}-C_{N_{0}}\right)} \\
& n_{\max }=5.4 \times 10^{7} \text { cells } / \mathrm{m} l
\end{aligned}
$$

$K_{N}+C_{N_{0}}$ denotes the nitrate concentration where the rate is reduced to half the maximum and was, in this case, $3 \mu \mathrm{mol} / l$. The degradation rate per unit cell, therefore, was roughly constant for each set and in the range of $(3.4-4.7) \times 10^{-12} \mathrm{mg} / \mathrm{cell} \cdot \mathrm{h}$, where the density of hexadecane is $0.773 \mathrm{~g} / \mathrm{m} l^{18)}$.

In Fig. 7, the degraded carbon $\triangle C$ and the uptake of nitrogen $\Delta N$ during the bracketed period were plotted against the average nitrate concentration for each set. $\Delta N$ was calculated as the sum of the amount of decrease in nitrate level and the amount of supplement. $\quad \Delta C$ was proportional to the degradation rates because the rates for all sets were calculated over the same time interval, while the uptake of nitrogen increased proportionately with nitrate level.

\section{Discussion}

\section{1 Comparison with previous works}

Below a certain level of substrate concentration, microbial activities are limited. There are two cases where nutrient concentrations are below this level: 1) the concentration in the ambient water is itself lower, though the water is replenished rapidly; 2) the concentration decreases due to microbial uptake and short supply of nutrients, even though the initial concentration might be much higher. Nutrient limitations in the open-sea environment will be similar to the former case, whereas limitations in batch culture are examples of the latter.

Experiments by Atlas and Bartha ${ }^{2 \text { ) }}$ and by Gunke ${ }^{12\}}$ employed batch incubation to compare the degradation of oils in unenriched medium with that in enriched ones. The poor degradation in the unenriched media was not attributable to the nutrient concentrations but simply to the nutrient supply, because their incubations were done with large dosages of oils and without nutrient supplement. Other experiments using an outdoor flow-through system by Atlas and Bartha ${ }^{3)}$ and by Atlas $^{5}$ were free from this difficulty, yet not quantitative. The semi-batch incubation we employed 
involved supplementary feeding of nutrients and could not always guarantee a constant level of substrate concentration. Yet with this method we could find an appreciable change in degradation rate at levels of nutrient concentration close to those of actual seawater.

Since the present study was concerned with the overall limitation of nutrient concentrations on biodegradation of oil, the ratios of nitrogen to phosphorus were fixed around 10, and according to these ratios, several levels of nutrient concentrations were chosen to simulate natural seawaters. The levels were represented by nitrate concentration. Therefore, we cannot conclude from these results which of the two nutrients was the actual limiting element for bacterial activity.

The present hydrocarbon dosage, $10 \mu l / l$, which was smaller than those of the other studies ${ }^{2,17}$, was chosen in order to diminish the carbon/nutrients ratios in the media. Lower ratios give smaller decrease of nutrient concentration for a given amount of carbon uptake during incubation and thus make it easier to keep nutrient concentration as nearly constant as possible. They also avoid an incubation condition where limitation by hydrocarbon transport from the bulk phase of oil to cells through aqueous phase becomes evident. This phenomenon, which was found and investigated well in hydrocarbon fermentation $^{15}$, was also found in Fig. 4 as the levelling-off over the range of 200-500 $\mu l / l$ of dosage.

The absolute degradation rates depend on the initial hydrocarbon dosage in batch incubation when nutrient concentrations are not limiting factors. The results with a marine Caulobacter by Murakami et al. ${ }^{17}$ ) are shown in Fig. 4. Although the incubation conditions were somewhat different from the present ones, both show a similar tendency. Murakami et al. also gave rates per unit cell ranging from $3.3-20 \times 10^{-12} \mathrm{mg}$ oil/cell $\cdot h$ for the Caulobacter and $4.8-34 \times 10^{-12} \mathrm{mg} /$ cell $h$ for a marine Flavobacter, respectively. Those of the present study were close to their lower values. Since the incubations were carried out batchwise with the same amount of inoculum, the differences in both cell growth and degradation rates among the sample sets are caused by the different activity of the microbes at different nutrient levels. The expression $r / n$, first proposed by Murakami et al., is an alternative measure for the activity when one cannot know total cell mass. The constant values of $r / n$ do not contradict the activity change by nutrient levels because $r / n$ includes the effects of both the change of mass of a cell and the cell yield as well as the activity usually shown by specific growth rate.

\section{2 Nutrient transport in actual oil spills}

The present results can be applied to the prediction
Table 2 Nutrient concentrations of seawater around Japan $[\mu \mathrm{mol} / l]$

\begin{tabular}{lcccc} 
& Ammonia & Nitrite & Nitrate & Phosphorus \\
\hline $\begin{array}{c}\text { Osaka Bay }{ }^{13)} \\
\text { (August) }\end{array}$ & 50 & 8 & 18 & $0.5-2.2$ \\
$\begin{array}{c}\text { Kuroshio } \\
\quad \text { August) }\end{array}$ & 0.1 & & 1.8 & 0.28 \\
$\begin{array}{c}\text { North Pacific } \\
\text { Ocean (April) }\end{array}$ & & $1-24$ & \\
\hline
\end{tabular}

of the limiting effects of nutrients on seeding of actual oil spills. Typical nutrient concentrations in seawater are summarized in Table 2. From this we might say that in coastal waters, such as Osaka Bay, oil degradation should occur without nutrient limitations. In oligotrophic or mesotrophic water like that of the Kuroshio, oil degradation will be slower and nutrientlimited; some artificial supplementation with nitrogen and phosphorus would be necessary when microbial seed organisms are added to the oil slick.

Several points, however, should be noted before arriving at this conclusion. In a laboratory experiment, it is easy to supply nutrients from the bulk water to the oil-water interface by vigorous shaking. In the natural environment, however, nutrient concentrations at the oil-water interface may become much lower than in the surrounding water mass if the transport of nutrients to the interface is a slow process. If this is the case, the rate of degradation would be much slower than that predicted from the nutrient concentrations in the bulk water.

We estimate this retardation effect on the transport process by use of a simple model. Let us assume that oil forms a thin film over the sea surface. Under the surface, mass is generally transported by turbulence and therefore the concentration is almost uniform. But in the vicinity of the surface, the concentration drops sharply. Taking the mass balance for nitrogen, we have

$$
K_{L}^{N}\left(C_{N}^{B}-C_{N}^{i}\right)=R\left(C_{N}^{i}\right) \frac{\Delta N}{\Delta C}
$$

where $C_{N}^{i}$ corresponds to $C_{N}$ in the experiment. The areal degradation rate, $R\left(C_{N}^{i}\right)$ is considered to depend on $C_{N}^{i}$ and will be obtained from the volumetric degradation rate data by multiplying it by the volume/ surface ratio of the experimental vessel. It was $1 \mathrm{~cm}^{3}$ / $\mathrm{cm}^{2}$ for our case. $\Delta N / \Delta C$ is given as its inverse in Fig. 6.

The mass transfer coefficient in the liquid film varies with conditions such as wind speed, water depth, current velocity, etc., especially in the sea. One way to estimate it is from the mass transfer coefficient of a gas for which the mass transfer resistance is known to be predominantly in liquid phase. Radon is such a gas and has a very low solubility. Emerson measured 
the $K_{L}$ for radon in small lakes when wind velocity was less than $2 \mathrm{~m} / \mathrm{sec}^{10)}$. The $K_{N}^{L}$ is expected to range from $2.7 \times 10^{-4}$ to $6.5 \times 10^{-4} \mathrm{~cm} / \mathrm{sec}$ if we assume that $K_{L}$ is proportional to diffusivity* and from $2.3 \times$ $10^{-4}$ to $5.5 \times 10^{-4} \mathrm{~cm} / \mathrm{sec}$ when we assume it varies with the root of diffusivity. The concentration drop $C_{N}^{B}-C_{N}^{i}$ is $0.39 \mu \mathrm{mol} / l$ at $C_{N}=4 \mu \mathrm{mol} / l$ when $K_{N}^{L}$ is $2.3 \times 10^{-4} \mathrm{~cm} / \mathrm{sec}$, and this drop lowers the degradation rate by $7 \%$ according to Eq. (1). Furthermore, $K_{L}$ in the sea is generally greater than that in lakes ${ }^{10)}$, and a much smaller decrease in degradation rate is expected. When a larger amount of oil is applied, the degradation rate increases and therefore the nutrient concentration drop would increase (Fig. 4). However, as indicated earlier, when larger hydrocarbon dosage was applied, emulsification occurred and the model does not apply. In this case, the concentration drop at the surface of emulsified oil droplets becomes smaller than at a flat surface. For crude oils or fuel oils, the decrease in rate may also be smaller due to their lower degradation rates.

\section{Conclusion}

1) The degradation rate of $n$-hexadecane by Bacillus decreased sharply at $2 \mu \mathrm{mol}$ nitrate $\mathrm{N} / l$ and $0.3 \mu \mathrm{mol}$ phosphate $\mathrm{P} / \mathrm{l}$ in a seawater medium. Above $4 \mu \mathrm{mol}$ nitrate $\mathrm{N} / l$ and $0.4 \mu \mathrm{mol}$ phosphate $\mathrm{P} / l$, the rate changed little.

2) The biodegradation is shown by use of a simple model to be virtually unretarded by the nutrient transport process from underlying water mass to the sea surface. In most eutrophic coastal seas, the biodegradation of oil is not limited by nutrient concentration, and the application of fertilizer is unnecessary when this bacterium is used as seed organism.

\section{Acknowledgment}

We thank Mr. N. Shiraishi, Faculty of Agriculture, Miss H. Takai and Mr. T. Nagase, Faculty of Science, University of Tokyo, for their cooperation in the experiment. We are also grateful to Dr. R. S. Farinato, Nearshore Environmental Research Center, Tokyo, for reviewing the manuscript.

This work was supported by Asahi Glass Foundation for Industrial Technology as a part of studies on "Use of sporeforming bacteria for enhancement of microbial degradation of spilled oils."

\section{Nomenclature}

$C_{N}$ $=$ nitrate concentration

$[\mu \mathrm{mol} / l]$

* Diffusivity for nitrate is assumed as $1.93 \times 10^{-5} \mathrm{~cm}^{2} / \mathrm{sec}$ from the data of those for potassium nitrate, $1.931 \times 10^{-5} \mathrm{~cm}^{2} /$ $\mathrm{sec}$, and for ammonium nitrate, $1.928 \times 10^{-5} \mathrm{~cm}^{2} / \mathrm{sec}$, both at $25^{\circ} \mathrm{C}$. Diffusivity for radon is $1.37 \times 10^{-5} \mathrm{~cm}^{2} / \mathrm{sec}$ at $25^{\circ} \mathrm{C}$ from the literature (8).

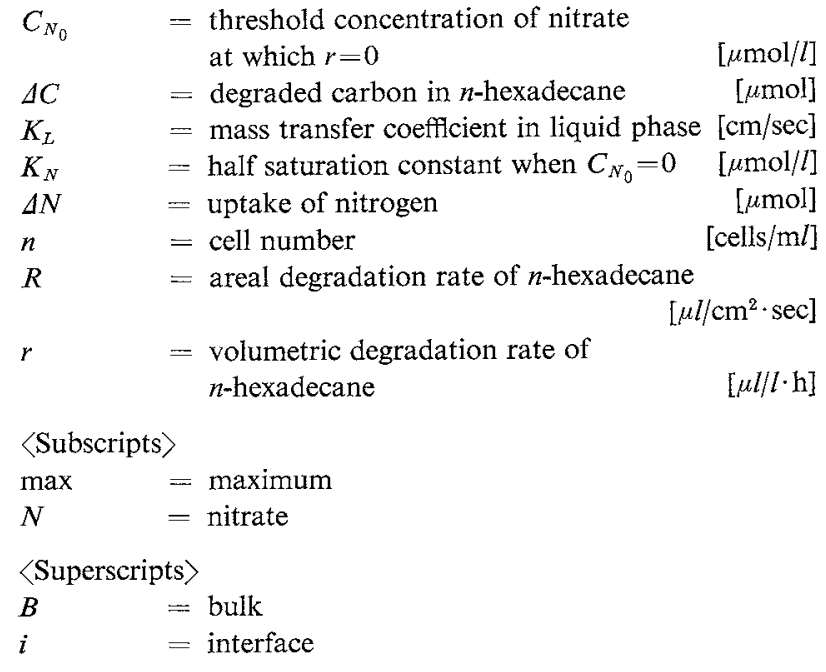

\section{Literature Cited}

1) Ahearn, D. G. and S. P. Meyers: "The Microbial Degradation of Oil Pollutants", Lousiana State University Publ. No. LSU-SG-73-01. Baton Rouge, LA. (1973).

2) Atlas, R. M. and R. Bartha: Biotechnol. Bioeng., 14, 309 (1972).

3) idem: Environ. Sci. Technol., 7, 538 (1973).

4) idem: in literature 1), p. 283 (1973).

5) Atlas, R. M.: Appl. Environ. Microbiol., 30, 396 (1975).

6) Atlas, R. M.: CRC Crit. Rev. Microbiol., 5, 371 (1977).

7) Bocard, C., B. Durif-Varambon, C. Gatellier and Ph. Renault: Proceedings, Oil Spill Conference, p. 407 API Publ., Washington D. C. (1977).

8) Broecker, W. S. and T.-H. Peng: Tellus, 26, 21 (1974).

9) Colwell, R. R. and J. D. Walker: CRC Crit. Rev. Microbiol., 5, 423 (1977).

10) Emerson, S.: Limnol. Oceanogr., 20, 754 (1975).

11) Floodgate, G. D.: Proceedings, Third International Biodegradation Symposium, Appl. Sci. Publ., London, 87 (1975).

12) Gunkel, W.: Helgoländer Wiss. Meeresunters., 15, 210 (1967).

13) Joh, H., R. Adachi and R. Miyoshi: Bull. Osaka Prefect. Fish. Exp. Stn., 3, 15 (1971).

14) Kawakami, Y. and H. Nishimura: Rep. Asahi Glass Found. Ind. Technol., (in press).

15) Mallee, F. M. and H.W. Blanch: Biotechnol. Bioeng., 19, 1793 (1977).

16) Meteorological Agency, Japan: Kaiyo Hokoku, 7, 59 (1958).

17) Murakami, A., T. Matsuda, N. Watanabe and S. Nagasawa: J. Oceanogr. Soc. Japan, 32, 242 (1976).

18) Nelson-Smith, A.: "Oil Pollution and Marine Ecology", 72, Elek Science, London (1972).

19) Sherpley, J. M. and A. M. Kaplan: Proceedings, Third International Biodegradation Symposium, Appl. Sci. Publ., London (1976).

20) Stephens, K.: Deep Sea Res., 17, 393 (1970).

21) Strickland, J. D. H. and T. R. Parsons: Fish. Res. Bd. Can., 169, 71 (1968).

22) Zobell, C. E.: Proceedings, API/FWPCA Conference on Prevention and Control of Oil Spills, API Publ. No. 4040, 317 (1969).

23) idem: in literature 1), p. 3 (1973). 